\title{
LO COMÚN: REFLEXIONES EN TORNO A UN CONCEPTO EQUÍVOCO
}

\section{Daniel Alvaro ${ }^{1}$}

\begin{abstract}
Resumen: Este artículo se propone reflexionar sobre las definiciones y teorías de lo "común" que alimentan los debates contemporáneos en torno a este concepto. Con ese objetivo se interrogan las obras de Christian Laval y Pierre Dardot, Michael Hardt y Antonio Negri, Jean-Luc Nancy y Roberto Esposito. Al analizar estos discursos queda en evidencia que lo que hoy se entiende por común, tanto desde un punto de vista filosófico como práctico-político, asume significados diferentes y muchas veces enfrentados entre sí. El artículo indaga los distintos significados y usos del concepto con el fin de demostrar que esta ambivalencia semántica es un factor decisivo para comprender los alcances y limitaciones del problema de lo común en el mundo actual.
\end{abstract}

Palabras clave: Común. Comunes. Equivocidad. Política. Ontología.

Debemos tener en cuenta el hecho de que lo "común” es una categoría que reviste lo que suelo llamar en francés "equivocidad" o significados equívocos: esto es, no solo una variedad de significados y aplicaciones, sino una tensión permanente entre significados opuestos.

Étienne Balibar

\section{LA IRRUPCión DE LO COMÚN. TeXTOS Y CONTEXTOS}

La palabra "común", empleada en singular, ya sea como adjetivo o como sustantivo, adquirió en el correr de las últimas décadas un estatuto conceptual hasta entonces desconocido. En la actualidad, la pregunta por lo común o, como también suele decirse, el común, se encuentra en el foco de intensos debates de los cuales participan autoras y autores, intelectuales, activistas y

\footnotetext{
${ }^{1}$ Consejo Nacional de Investigaciones Científicas y Técnicas / Universidad de Buenos Aires - Instituto de Investigaciones Gino Germani. (iD https://orcid.org/0000-0003-0498-1670. E-mail: danielalvaro@ gmail.com. Buenos Aires, Argentina.
}

http://dx.doi.org/10.1590/0101-3173.2020.v43n4.05.p89 
militantes con orientaciones teóricas y prácticas muy diversas. La pluralidad de marcos de referencia y el gran número de disciplinas desde las cuales hoy se intenta dar respuesta a esta pregunta son indicios de la riqueza y complejidad que encierra el concepto en cuestión.

Aunque los planteos que indagan lo común sean todos ellos de fecha reciente, la palabra misma y las múltiples ideas que esta vehiculiza circulan desde tiempos remotos. Tanto en el vocablo griego koinos como en el vocablo latino communis - del cual deriva el término "común"- resuenan algunas de las grandes tradiciones teológicas, filosóficas, políticas y jurídicas sobre las cuales se erigió la cultura occidental. Lo cual es tanto como decir que el motivo de lo común, emparentado semántica y etimológicamente con los motivos de la comunidad, la comunión, la comunicación, etc., ha constituido desde la Antigüedad clásica un asunto de discusión privilegiado en Occidente. Pero lo que caracteriza a los discursos contemporáneos, y aquello que los diferencia de los alegatos clásicos y modernos que bordearon el asunto con mayor o menor penetración, es la tentativa de ofrecer una definición conceptual y una teoría de lo común.

En este artículo nos proponemos echar luz sobre las principales definiciones y teorías que es posible distinguir en el estado actual de los debates abiertos en torno a este inmenso problema. Para ello tomaremos como referencia las obras de algunos autores que en los últimos decenios reconocieron la necesidad de elaborar una concepción de lo común desde puntos de vista filosóficos y políticos. Contrariamente a lo que tal vez se podría esperar, aquí no se intentará una interpretación genealógica ni un trabajo de historia conceptual. Tampoco es nuestra intención catalogar el cúmulo de producciones que hoy en día asumen como tarea pensar el estatuto de lo común. El objetivo de esta exposición es mucho más modesto y por lo demás enteramente programático. Este consiste en reflexionar sobre diferentes usos y significados del concepto de lo común a partir del análisis de una serie acotada de textos donde a nuestro juicio quedan expuestas las principales apuestas teórico-prácticas sobre este problema. Concretamente, analizaremos textos de Christian Laval y Pierre Dardot, Michael Hardt y Antonio Negri, Jean-Luc Nancy y Roberto Esposito. Esta selección obedece entre otras cosas a dos razones de peso que es importante tomar en cuenta para todo lo que sigue. En primer lugar, porque sin ser los únicos, son ellos, sobre todo, quienes hasta ahora han conducido más lejos el pensamiento y la posibilidad de experiencias innovadoras alrededor de lo común. Cualquiera sea el modo 
en que se interprete la pertinencia de sus propuestas, la importancia y la influencia de sus teorías en la actualidad está fuera de discusión. En segundo lugar, porque sus respectivas posiciones políticas y filosóficas, epistemológicas y metodológicas, permiten ver con claridad la ambivalencia o, para decirlo con la palabra empleada por Balibar en la frase que usamos como epígrafe, la "equivocidad" que recorre de parte a parte la comprensión de lo común. Se trata, pues, de discursos que comparten la inquietud por determinar el alcance de esta categoría y que, al mismo tiempo, difieren notablemente en cuestiones fundamentales que van desde la consideración del punto de partida hasta las motivaciones prácticas que los animan. Sobre la base de estas diferencias-que por cierto no excluyen afinidades y reconocimientos explícitos entre algunos de los teóricos mencionados-, intentaremos dar cuenta del conglomerado que forman estos discursos a fin de evidenciar el carácter equívoco que tensa lo "común" entre significaciones diferentes y en ciertos casos opuestas ${ }^{2}$.

Antes de comenzar el análisis conviene tener presente las coordenadas del surgimiento de lo común en cuanto concepto relativamente autónomo y, por lo tanto, diferenciable de otras nociones afines. A grandes rasgos, se puede decir que la problemática de lo común irrumpió de manera más o menos simultánea en tres contextos móviles y parcialmente superpuestos. El primer contexto al que vamos a referirnos abarca el conjunto de reivindicaciones de los "comunes" (commons) que llevan a cabo actores y movimientos sociales contra la nueva tendencia a los "cercamientos" (enclosures) propiciados por el capitalismo globalizado. Lo que desde aproximadamente 1990 se suele entender por comunes, tanto en las teorías que lo explican como en las luchas ecológicas y anticapitalistas que se libran en su nombre alrededor del mundo, oscila entre más de un sentido. Puede aludir tanto a los recursos de uso común (naturales, técnicos, culturales, materiales, inmateriales, etc.) que se intenta preservar de la simple destrucción o de la apropiación privada, con o sin colaboración por parte del Estado, como a experiencias y espacios de participación con capacidad de incidir sobre una nueva organización de la sociedad. La reivindicación de los comunes, en el sentido amplio de la palabra, provocó un renovado interés por lo común al mismo tiempo que una confusión generalizada entre estos términos. En esta singular coyuntura, Hardt y Negri (2002 y 2004) son los responsables de una primera distinción analítica entre

\footnotetext{
${ }^{2}$ Los discursos analizados en este artículo han sido objeto de una profunda y exigente investigación por parte de Matías Saidel en los últimos ańos. De los numerosos trabajos donde se dedica a interpretar las diferentes posiciones en debate, y con los cuales compartimos más de un punto en común, remitimos a su último artículo publicado sobre el tema: Saidel (2019).
} 
ambos conceptos a partir de una estrategia que tiende a combinar el enfoque ontológico y el político. Tras sus pasos, aunque sin privarse de una crítica profunda a sus postulados básicos, Laval y Dardot (2015) también se vieron llevados a establecer una diferencia conceptual en este sentido y a proponer su propia teoría de lo común desde un punto de vista práctico-político.

El segundo y el tercer contexto son más acotados y tienen, en todos los planos, un alcance más limitado que el primero. Pensamos, por un lado, en el debate sobre la cuestión de la "comunidad" tal como se dio desde mediados de la década de 1980 en Francia y luego en Italia, y, por otro lado, en las polémicas mucho más recientes que tuvieron lugar fundamentalmente en Europa, América y Asia a propósito del "comunismo" en cuanto idea filosófica. En el transcurso de los últimos cuarenta años, el interés por la comunidad y la cosa comunitaria en general atravesó los más variados ámbitos de investigación ligados a las ciencias sociales y las humanidades. Pero fue en el ámbito que interroga la comunidad desde una perspectiva filosófica, y más específicamente ontológica, donde surgió casi de forma paralela la pregunta por lo común. El libro pionero de Nancy (2000), junto al de otros pensadores franceses entre los que se destaca Maurice Blanchot (2002), son acaso los más representativos de una perspectiva orientada a problematizar el ser de lo común y de la comunidad. El debate iniciado en Francia conoció una prolongación en Italia principalmente a través de las obras de Esposito (2003) y Giorgio Agamben (2006). Si bien estos trabajos se ocupan ante todo de cuestiones metafísicas, ninguno de ellos es indiferente a las implicaciones políticas de las nociones comunitarias que ponen en juego, en particular en lo que respecta a su articulación con la experiencia comunista. Con todo, la indagación más sistemática sobre la "idea del comunismo" -según la expresión de Alain Badiou- cobró impulso en los últimos diez años y por sus características constituye un contexto aparte de los anteriores. La pesquisa se articuló alrededor de una sucesión de intervenciones públicas consagradas a la temática, de las cuales participaron académicos y académicas cuyos vínculos con la "realidad" y la "idea" del comunismo son en extremo heterogéneos ${ }^{3}$. A efectos de este análisis, lo que importa subrayar es el hecho de que no pocas de estas contribuciones se abocaron a explicar la relación entre lo común y el

\footnotetext{
3 Bajo el título general, "La idea del comunismo", se celebraron cuatro conferencias internacionales: en Londres en 2009 (HOUNIE, 2010), en Berlín en 2010 (BADIOU; ŽIŽEK, 2011), en Nueva York en 2011 (ŽIŽEK, 2014), y en Seúl en 2013 (TAEK-GWANG; ŽIŽEK, 2018). Entre otras intervenciones de este tipo realizadas recientemente cabe destacar La conferenza di Roma sul comunismo de 2017, cuyo registro textual y audiovisual se encuentra diseminado en internet.
} 
comunismo. Entre ellas hay que incluir las contribuciones de algunos de los autores cuyos textos revisaremos, como así también las de tantos otros y tantas otras que abordan teóricamente esta relación (sobre todo, pero no de manera exclusiva, Slavoj Žižek, Étienne Balibar, Jacques Rancière, Susan Buck-Morss, Jodi Dean, Bruno Bosteels y Álvaro García Linera).

He aquí una breve delimitación sobre la triple procedencia de aquello que hoy se entiende y se disputa bajo el nombre de "común". Incluso si este concepto no se confunde con las figuras de los comunes, de la comunidad o del comunismo, es preciso constatar desde el comienzo que no es posible aislarlas ni prescindir de ellas puesto que lo común irrumpe en el seno de una constelación que necesariamente las incluye.

\section{Lo COMÚn COMO PRINCIPIO POLÍtico: LAVAL Y DARDOT}

El libro de Laval y Dardot, Común. Ensayo sobre la revolución en el siglo XXI (2015), se distingue del resto de los escritos que vamos a analizar por motivos que es oportuno enumerar. En primer lugar, por razones de orden fáctico. La teoría de lo común allí plasmada es comparativamente más cercana en el tiempo que aquellas elaboradas por Hardt, Negri, Nancy y Esposito. Este hecho supone entre otras cosas que el discurso de Laval y Dardot se instala, por decirlo así, en un campo problemático definido, lo cual les permite evaluar su nueva apuesta en relación con otras ya existentes. En segundo lugar, Común es el único texto de esta serie donde se confrontan las tesis que sus contemporáneos ponen a prueba sobre el mismo problema. A esto hay que agregar que, además de ofrecer un riguroso desarrollo conceptual, el texto se plantea tres objetivos de largo aliento: 1) reconstruir el contexto histórico donde emerge lo común y examinar de modo crítico los razonamientos políticos, económicos, filosóficos y jurídicos sobre el tema; 2) describir genealógicamente la relación entre lo común, el derecho y la institución en la historia de Occidente; 3) presentar a grandes trazos, bajo la forma de nueve propuestas concretas, en que consiste o debería consistir una política de lo común. Huelga decir que no son méritos menores, sobre todo si se tiene en cuenta que ninguno de los autores considerados en este artículo lleva adelante un trabajo de tal magnitud.

Se trata de una obra desmesurada, potente y original. En virtud de su admirable riqueza, Común amerita un análisis más extenso y dedicado que el que estamos en condiciones de realizar aquí. De momento nos concentraremos 
en aquellos aspectos que aporten una visión de conjunto sobre la obra, donde quede claramente expuesta la posición de Laval y Dardot para después contrastarla con las posturas adoptadas por los otros autores de los que se ocupa este artículo.

Para empezar, hay que tomar nota del diagnóstico general del que se parte en Común. La fórmula que resume el estado de la humanidad en la actualidad es "la tragedia de lo no-común" (LAVAL; DARDOT, 2015, p. 18). La tragedia a la que se hace referencia es la de la humanidad "bajo el control de los grupos económicos, las clases sociales y las castas económicas que, sin ceder nada en cuanto a derechos y privilegios, quisieran prolongar el ejercicio de su dominio alimentando la guerra económica, el chantaje del paro y el miedo a los extranjeros" (LAVAL; DARDOT, 2015, p. 18). Lo que se describe así es un drama de proporciones mundiales fomentado por las políticas neoliberales. La principal responsabilidad del estado de cosas actual recae sobre el mercado y el Estado, el cual se encuentra cada vez más sometido a poderes económicos que ya no puede controlar. En un libro anterior, Laval y Dardot (2013) se habían propuesto dilucidar políticamente la lógica neoliberal o, como prefieren llamarla, "la nueva razón del mundo". Contra la lógica del capitalismo contemporáneo, llamaban a pensar y poner en práctica una racionalidad completamente distinta. "A esta razón alternativa, no podría dársele mejor nombre que éste: la razón del común" (LAVAL; DARDOT, 2013, p. 409). Significativamente, con estas palabras concluye el libro. Allí la cuestión del común es apenas insinuada como el nombre bajo el cual podrían agruparse acciones diversas tendientes a transformar el presente con vistas a otro porvenir. Esta tarea, hasta entonces solo afirmada como una necesidad, fue acometida de manera audaz en Común, texto que puede leerse como la segunda parte de la trilogía que empieza con La nueva razón del mundo y termina con La pesadilla que no acaba nunca (LAVAL; DARDOT, 2017).

En Común se deja en claro desde el arranque que, aunque "nada podrá reemplazar el compromiso con la acción", el esclarecimiento de "nuevas perspectivas sobre un más allá del capitalismo" es "indispensable” (LAVAL; DARDOT, 2015, p. 20). Como se ha dicho ya, estas perspectivas son teóricas y prácticas o propositivas. Entre las primeras hay que contar un agudo trabajo de clarificación conceptual. Pero antes de que consideremos este trabajo, es preciso saber que el planteo de Laval y Dardot se basa directamente en las luchas sociales que bajo formas organizativas y discursivas muy diferentes enarbolan la bandera de lo "común" y los "comunes" como contestación al 
neoliberalismo. En sus propias palabras, el objetivo que persiguen es "refundar el concepto de común de forma rigurosa, y ello rearticulando las prácticas que a día de hoy encuentran en él su sentido con cierto número de categorías e instituciones" (LAVAL; DARDOT, 2015, p. 22, el énfasis es de Laval y Dardot). Esta aclaración preliminar sirve, por una parte, para situar su propio discurso en un terreno político determinado y, por otra, para mostrar que la pretensión de "refundar el concepto" aludido, y hacerlo "de forma rigurosa", responde a la percepción que tienen los autores del modo impreciso y en general limitado de las concepciones actuales de lo común.

Laval y Dardot (2015, p. 28) emprenden una "arqueología de lo común", justamente, para "librarse de las banalidades, confusiones y contrasentidos" que rodean a esta palabra en sus usos contemporáneos. Con ese fin, recurren a la etimología del latín commune, formado por los términos cum, del cual deriva la preposición "con", y munus, que significa simultáneamente una "obligación" y una "actividad" o "tarea" de carácter social y a menudo política. Por razones de espacio, haré la economía de esta exégesis filológica para ir directamente a las conclusiones que se derivan de ella:

La consecuencia que aquí extraeremos es que el término "común" es particularmente apto para designar el principio político de una coobligación para todos aquello que están comprometidos en una misma actividad. [...] En sentido estricto, el principio político de lo común se enunciará, por tanto, en estos términos: "sólo hay obligación entre quienes participan de una misma actividad o en una misma tarea". Excluye, en consecuencia, que la obligación se funde en una pertenencia dada independientemente de la actividad (LAVAL; DARDOT, 2015, p. 29).

A partir de esta definición inicial es posible deducir las principales características de lo común entendido como principio político. Para empezar, el énfasis está puesto en la obligación y la participación recíprocas que concierne a los individuos implicados en una misma acción. Para decirlo de manera tajante, lo común no es nada por fuera de la "co-actividad" o, más precisamente, del "actuar común”. Esta noción está inspirada en la concepción del “"poner en común' (koinonein)” desarrollada por Aristóteles en la Política. Se trata de una concepción "verdaderamente matricial" para los propósitos de Laval y Dardot (2015, p. 30) ya que "hace de la práctica de la puesta en común la condición misma de todo lo común”. Esto quiere decir que lo común depende enteramente del actuar común. En tanto y en cuanto éste es condición de aquél, queda obliterada de entrada la posibilidad de identificar 
lo común con cualquier clase de dato natural que preexista a la actividad. De ahí que lo común no deba confundirse con el "bien común" (en el sentido de finalidad última, sea política o religiosa), ni con los "bienes comunes" (en el sentido de cosas en sí mismas comunes), ni con lo "universal" (en el sentido de lo que por naturaleza tenemos en común como humanidad), tal como sugieren, respectivamente, buena parte de las tradiciones teológico-políticas, jurídicas y filosóficas de Occidente. De un modo u otro, estas tradiciones terminan por reafirmar un esquema esencialista, multiplicando así los escollos para establecer "un concepto verdaderamente político de lo común" (LAVAL; DARDOT, 2015, p. 32). Según Laval y Dardot, lo común no es una esencia o una sustancia, como tampoco es un objeto ni una cosa apropiable de hecho o de derecho. En rigor, "común" - tomado como sustantivo y no como adjetivo, de acuerdo al uso que se promueve a lo largo de todo el texto - es un "principio". Es la razón política de los combates y los discursos críticos que se oponen a la razón neoliberal en el tiempo presente. El principio de lo común designa la nueva racionalidad, el nuevo sentido que guía aquellas prácticas orientadas a inventar formas democráticas alternativas en el marco de un proyecto revolucionario consecuente con los desafíos del siglo XXI. La esperanza de un "más allá del capitalismo" no está depositada en el renacimiento del Estado bajo ninguna de sus formas, sino más bien en la construcción de una democracia radical basada en la autonomía colectiva. Sintetizando al máximo la idea de "revolución" que manejan Laval y Dardot (2015, p. 656-659), se puede decir que esta consiste -según la fórmula de Cornelius Castoriadis que ellos adoptan y reactualizan - en la "autoinstitución de la sociedad". Instituir la sociedad a partir de sí misma implica mínimamente la creación de "comunas" o instituciones políticas y económicas de autogobierno que, organizadas en un sistema federativo, sean capaces de producir nuevas reglas de derecho para garantizar la inapropiabilidad de los recursos y espacios destinados al uso común que aquí reciben el nombre de "comunes". La actividad que crea estas reglas de derecho a partir de la transformación de lo ya creado es lo que Laval y Dardot (2015, p. 459-512) denominan "praxis instituyente". Esta praxis es revolucionaria en tanto en cuanto instituye el derecho de uso en oposición directa a la propiedad privada o estatal, y en la medida en que hace de este derecho el resorte indispensable para la reorganización de la sociedad.

Hasta acá, todo el planteo es coherente con la idea que se afirma desde el comienzo: lo común no está dado naturalmente, sino que se construye a través de la acción de los seres humanos. Nada del orden de lo común precede a la construcción de lo común, salvo el acto de su propia institución: "la 
actividad de institución de lo común sólo puede ser común, de tal manera que lo común es al mismo tiempo una cualidad del actuar y aquello que este actuar instituye" (2015, p. 318). Incluso este aspecto paradójico de la teoría no deja de guardar cierta coherencia con la tesis que los autores ponen a prueba, a saber, que lo común llega a existir y a perdurar en el tiempo únicamente gracias al actuar común. Lo que a nuestro modo de ver resulta contradictorio y hasta desconcertante es la re-definición del "principio de lo común" que se lee en las últimas páginas del libro, más exactamente en el añadido final titulado "Post-scriptum sobre la revolución en el siglo XXI" (2015, p. 649-665).

En esta suerte de postdata, Laval y Dardot (2015, p. 660) explican qué entienden por principio: “¿Qué es un principio? Un principio es lo que aparece primero y funda todo el resto". Afirman que el término debe ser entendido en su acepción filosófica clásica, a la manera en que Aristóteles concibe la arché en la Metafísica, esto es, como "comienzo" y como "imperativo: "la fuente de la que todo lo demás se deriva” (LAVAL; DARDOT, 2015, p. 660). Asimismo, se dice a continuación, principio tiene un significado lógico, en cuanto "premisa de un razonamiento o una demostración" que sirve de antecedente a las nueve propuestas políticas que se presentan en el libro. Así se llega a esta definición terminante: "Lo común es un principio político en el sentido de que ordena, impone y rige todo en la actividad política" (LAVAL; DARDOT, 2015, p. 660). Quien haya seguido atentamente la lectura de Común hasta el final, difícilmente pueda evitar la sensación de desconcierto ante este repliegue inesperado en el dominio de la metafísica. Equiparar el principio de lo común con la arché aristotélica, es decir, con el comienzo, con el imperativo y el mandato, con el fundamento o el origen de todas las cosas, no solo es contradictorio con la definición de lo común que analizamos más arriba, también es contradictorio con el planteo general de la obra. No hay que olvidar que para Laval y Dardot se trata ante todo de refundar el concepto de común en el terreno de las luchas políticas, económicas y jurídicas que dependen de la praxis humana, con el objetivo de desterrar las teorías viejas y nuevas que tienden a naturalizar lo común.

Llamar la atención sobre este contrasentido tiene aquí una doble motivación. Por un lado, es una manera de ratificar la interpretación de Balibar sobre la equivocidad de este concepto, incluso dentro un mismo programa teórico. Por otro lado, es una invitación a problematizar un discurso que se propone instaurar una nueva y esclarecida concepción de lo común asentada en una crítica muy atenta a las limitaciones que afectan a otras concepciones 
sobre el mismo asunto, pero que sin embargo desatiende sus propios límites y contradicciones. Esto último nos interesa en particular puesto que el cuestionamiento que Laval y Dardot dirigen a Hardt y Negri, a Nancy y a Esposito, denuncia puntos ciegos en sus teorías de los que el propio discurso cuestionador no está exento.

\section{Lo COMÚN COMO CONDICIÓN ONTOLÓGICA: HaRDT y Negri, NANCY y ESPOSITO}

Una de las primeras alusiones a "lo común" en la obra conjunta de Hardt y Negri se encuentra en Imperio. Allí plantean la pregunta acerca de "cuál es la noción operativa de lo común en nuestros días, en medio de la posmodernidad” (HARDT Y NEGRI, 2002, p. 267), caracterizada por el predominio del sector servicios sobre otros sectores antiguamente dominantes en la economía y, más ampliamente, por la revolución informática del modo de producción capitalista. Sin embargo, esta pregunta recién obtendrá respuestas concretas en los dos libros que continuaron la trilogía iniciada con Imperio: Multitud (2004) y Commonwealth (2011). En ellos, la noción de lo común se articula con muchas otras al interior de una teoría filosófica y política de vasto alcance. Nos limitaremos a indicar sus rasgos más generales a fin de avanzar con nuestro objetivo.

Mediante la apelación a lo común, en singular, Hardt y Negri (2004, p. 17) se proponen "subraya[r] el contenido filosófico del término", diferenciándolo así de los comunes, en el sentido tradicional de "los espacios comunales de uso compartido en la época precapitalista". Ciertamente, lo común es una categoría filosófica con implicancias en todas las esferas de la vida social que adquiere especial relevancia en el contexto de la globalización. Dicho de forma esquemática, Imperio es el nombre de un nuevo orden soberano a escala planetaria que se compone tanto de instituciones nacionales como supranacionales y es una de las caras de la globalización. La otra cara es la Multitud, y por ella hay que entender un nuevo sujeto social distinto del "pueblo", las "masas" y la "clase obrera", en la medida en que posee una estructura en red de carácter abierto, diverso en cuanto a su identidad, inclusivo y horizontal. El desafío político de la multitud consistiría en enfrentar la soberanía imperial, junto al estado de guerra permanente que ella engendra, con el propósito de crear una sociedad global alternativa, democrática, autónoma y pacífica. Lo común, tal como Hardt y Negri lo entienden, es inseparable del concepto y del proceso revolucionario que encarna la multitud. 
Inseparable en un doble sentido: por un lado, la "constitución” y la "acción" de la red de singularidades que forman la multitud "se fundan [...] en lo que hay en común", vale decir, en "lo compartido por esas singularidades" (HARDT Y NEGRI, 2004, p. 128), y, por otro lado, este nuevo sujeto social "produce en común y produce lo común" (HARDT Y NEGRI, 2004, p. 385) mediante las fuerzas económicas, políticas y culturales movilizadas por el "trabajo inmaterial" que, según la conocida tesis de Hardt y Negri, tiende a ser la forma de trabajo hegemónica en la actualidad (HARDT Y NEGRI, 2004, p. 136-137).

En consecuencia, se puede afirmar que lo común es tanto la condición ontológica como el resultado productivo de la multitud. Sin dejar de reconocer la aparente incompatibilidad de esta idea, los autores invitan a pensar los dos sentidos de lo común de manera simultánea y en relación recíproca. "Paradójicamente, lo común aparece en ambos extremos de la producción biopolítica: es el producto final y la condición preliminar de la producción. Lo común es al mismo tiempo natural y artificial, es nuestra primera, segunda, tercera y enésima naturaleza” (HARDT Y NEGRI, 2004, p. 396). La producción biopolítica, impulsada por el trabajo inmaterial, se basa en lo común compartido y produce lo común que se comparte a su vez. Por medio de este proceso en espiral, los recursos naturales y artificiales, materiales, intelectuales y afectivos que configuran lo común se refuerzan mutuamente y transforman la vida social en su conjunto. Para evitar una lectura simplista de semejante proceso, hay que tener en cuenta que lo común no es menos representativo del poder constituyente de la multitud que del poder imperial del capital global. En otras palabras, lo común es inmanente al "ser social" existente, con todas las riquezas y miserias que le son propias y que hacen de este una realidad contradictoria, conflictiva y cambiante (HARDT Y NEGRI, 2004, p. 189-190).

Así se explica que la naturaleza común de la multitud no garantice para ella una orientación política determinada (HARDT; NEGRI, 2011, p. 187188). La multitud es una subjetividad social potencialmente revolucionaria, pero su deriva progresiva o regresiva depende de interacciones sociales específicas. De manera que la posibilidad de la liberación y el autogobierno de la multitud está subordinada a su propia capacidad de decisión y organización políticas. Se trata de un hecho que debe ser comprobado en la práctica, no de un dato necesario. En verdad, nada está dado de una vez y para siempre en lo que refiere a este modo de abordar y definir lo común. Ni siquiera su 
aspecto ontológico. Tanto en las publicaciones que citamos aquí como en otras posteriores $^{4}$, Hardt y Negri insisten en explicar que su ontología -inspirada sobre todo en las filosofías de Spinoza, Marx y Foucault, las cuales aportan elementos teóricos y metodológicos- es eminentemente social e histórica. En efecto, esta no es abstracta ni especulativa, sino que es ontología de la producción y reproducción de la vida en todos los planos imaginables de la misma. Las relaciones de fuerza y poder que se entrelazan en el plano económico, político, cultural y existencial forman parte en la misma medida y de manera intercambiable de la constitución ontológica del mundo. Todo esto da lugar a una concepción del ser en continua transformación de sí mismo, esto es, en proceso de devenir por las relaciones y prácticas en común. "Al fin y al cabo, el ser no es sino otra manera de decir lo que es ineluctablemente común, lo que se niega a ser privatizado o cercado y permanece constantemente abierto a todos. (No hay nada que pudiéramos llamar ontología privada.)" (HARDT; NEGRI, 2011, p. 191). Como se habrá advertido, las dimensiones ontológica, social y política de lo común se encuentran estrecha y rigurosamente vinculadas en esta teoría. Acaso la contribución más importante y original de estos autores a los debates actuales sobre lo común consista en haber encontrado una manera de reunir dimensiones que habitualmente pasan por ser irreconciliables.

La aproximación de Nancy a lo común es el resultado de una larga elaboración filosófica que comenzó en la década de 1980 y continúa hasta la actualidad. La ocurrencia del "ser-" o "estar-en-común" (être-en-commun), es decir, la idea de que el ser o el estar cada vez singular se da siempre en plural, ya se encuentra desarrollada en su primer libro dedicado a la cuestión de la comunidad. Allí escribe: “¿Hay algo más común que el ser, que estar? Estamos. Lo que compartimos es el ser, o la existencia. [...] El ser está en común. ¿ Hay algo más simple de constatar? Y, con todo, ¿qué ha sido más ignorado, hasta ahora, por la ontología?” (NANCY, 2000, p. 139). Afirmar que el ser está en común significa que la existencia es de entrada relacional, numerosa y compartida. $\mathrm{O}$, dicho de otro modo, que no hay ni puede haber ser sin otro ser. Desde un punto de vista ontológico, esta afirmación comporta un rechazo terminante de cualquier pensamiento del ser que tome a éste como esencia, sustancia o sujeto. Con el sintagma être-en-commun se intenta hacer patente que el ser no existe con anterioridad a una pretendida relación posterior que vendría a ponerlo en comunicación con otros seres. Es en la relación, y a partir de ella, que los seres llegan a la existencia. El ser tiene lugar

${ }^{4}$ Véase, por ejemplo, Hardt y Negri (2012 y 2019). 
en-común, junto a, con y contra otros seres, o, de lo contrario, no tiene lugar en absoluto. En la ontología de Nancy, lo común es constitutivo del ser, de un modo semejante, aunque más radical, a la manera en que la ontología heideggeriana presenta el ser-con (Mitsein) como esencialmente implicado en el ser-ahí (Dasein). La impronta de Heidegger, como es evidente, pero también la de Rousseau, Nietzsche y Marx son reconocibles en esta filosofía. Una vez dicho esto, es conveniente recordar que esta meditación tiene su origen en una inquietud política. La pregunta que Nancy se plantea en los años 80, y que en cierta forma marcará todo su recorrido ulterior, puede formularse en estos términos: ¿cómo pensar lo común y la comunidad sin recurrir a los clásicos fundamentos teóricos y conceptuales que han servido para apuntalar tanto a los totalitarismos de izquierda y de derecha como al individualismo democrático? Lo que ya por entonces resultaba claro era que para concebir y promover formas alternativas de relacionamiento social, económico y político se hacía completamente necesario dejar atrás la idea tradicional del ser, ya sea individual, ya sea colectivo, entendido como una totalidad inmanente, clausurada sobre sí misma y, por consiguiente, entregada a su pura interioridad.

Ahora bien, si se intenta ir directamente al corazón de lo que está en juego en esta propuesta donde las motivaciones políticas corren a la par de las filosóficas, se podría decir que para Nancy (2016, p. 14) lo común se presenta de dos formas correlativas y simultáneas:

Por lo común hay que entender a la vez lo banal, es decir el elemento de una igualdad primordial e irreductible a todo efecto de distinción, e indiscerniblemente- lo compartido, es decir lo que no tiene lugar más que en la relación, por ella y como ella: en consecuencia, lo que no se resuelve ni en "ser" ni en "unidad".

Hay, pues, lo común: la evidencia banal de la igualdad entre seres cuya singularidad es indisociable de la pluralidad que los constituye. Y, en cierto modo, para la ontología del ser singular plural no hay más que eso. En el sentido de que la totalidad de lo existente supone el régimen general de la relación o la compartición (partage), de la alteridad y la exposición entre seres indistintamente distintos, vale decir, el régimen de lo común. Lo que aquí se denomina común es la condición ontológica de todo lo que es. Entendemos que esta formulación es adecuada para interpretar el pensamiento de Nancy siempre y cuando no se confunda la condición ontológica, que es el espaciotiempo del existir mismo, con un principio trascendente o inmanente, ni 
se identifique lo común con una esfera determinada de la existencia. En la tradición metafísica ambos gestos muy a menudo aparecen entrelazados. En particular, como sucede desde Platón y Aristóteles, cuando se convierte a la esfera política en depositaria y garante de la verdad de lo común.

Lejos de confirmar esta proximidad históricamente determinada entre lo político y lo común, Nancy insiste en separar cuanto sea posible estos dos órdenes. Según explica en algunas de sus publicaciones recientes, esto sería indispensable para evitar que la política asuma el sentido de la existencia en general y, de esta suerte, se establezca como principio y fin de lo común, tal como pretendieron los totalitarismos comunitarios o comunitaristas y como todavía pretenden las democracias actuales. Esta separación, sin embargo, no convalida la anulación del vínculo inextricable entre política y ser en común. Más bien incita a pensar la política como un orden aparte y determinado, cuya especificidad "consiste en articular juntos los diferentes elementos de la existencia común, pero sin ser ella misma, la política, la cosa común en general" (NANCY, 2009, p. 102). La posición de Nancy a este respecto adquiere consistencia en su crítica a la máxima "todo es político", la cual implica de un modo u otro la reducción de la vida en común a lo que no sería más que una de sus esferas 5 .

Esposito, al igual que Nancy y siguiendo sus pasos, comienza a desarrollar su teoría de lo común a partir de una reflexión sobre la idea de comunidad. En Communitas (2003), primera entrega de la trilogía que se completa con Immunitas (2005) y Bíos (2006a), Esposito (2003, p. 23) se lanza a una crítica vehemente de los modos en que la filosofía política a través de algunas de sus corrientes modernas y contemporáneas (organicismo, neocomunitarismo, ética del discurso, comunismo, etc.) suele representarse la comunidad, esto es, como objeto o sujeto, como origen o destino, como sustancia o propiedad: "En todos los casos, como lo que nos es más 'propio"”. Aquello que según Esposito liga a los pensamientos filosófico-políticos de la comunidad es que, para todos ellos, lo que es común a los miembros de una comunidad termina por identificarse con la lógica del proprium, ya sea bajo la forma de la apropiación, de la pertenencia o de la posesión. Cuando en realidad -tal es la hipótesis que se propone demostrar en este libro- "común" y "propio" se oponen por definición, o más bien por etimología:

El primer significado que los diccionarios registran del sustantivo communitas, y del correspondiente adjetivo communis, es, de hecho, el que adquiere sentido

5 A propósito de las implicaciones ontológicas y políticas de esta crítica, véase en especial Nancy (2001). 
por oposición a "propio". En todas las lenguas neolatinas, y no sólo en ellas, "común" (commun, comune, common, kommun) es lo que no es propio, que empieza allí donde lo propio termina (ESPOSITO, 2003, p. 25-26).

La interpretación etimológica de Esposito coincide, al menos en parte, con aquella que Laval y Dardot realizarían años más tarde y sobre la cual hablamos más arriba. Sin embargo, entre una y otra subsisten diferencias importantes, tanto en lo relativo al cum como al munus, que conducen necesariamente a conclusiones muy distintas. Esposito empieza por desligar el munus de sus significaciones más divulgadas de "público", "general" o "colectivo", para religarlo a la idea de "deber" donde el vocablo latino encuentra toda su complejidad. El deber comporta el triple significado de obligación, empleo o cargo, y don. Si bien la idea de deber es manifiesta en los dos primeros significados, no lo es tanto en el tercero. Por esta razón el autor aclara enseguida que no se trata de un don voluntario sino obligatorio, ya que está asociado al intercambio. Sin embargo, el munus es el don que se da y no el que se recibe. Implica pérdida y privación, no ganancia. Así se explica que Esposito pueda arribar a la siguiente deducción: "el munus que la communitas comparte no es una propiedad o pertenencia. No es una posesión, sino, por el contrario, una deuda, una prenda, un don-a-dar" (ESPOSITO 2003, p. 30). Lo que vincula a los sujetos de la comunidad es, en definitiva, una falta o una carencia, una ausencia o un vacío que mantiene a los sujetos fuera de sí, es decir, expuestos a sí y entre sí. Por esta vía hermenéutica se llega a esta proposición paradójica: antes que una identidad o una subjetividad cerrada sobre sí misma, lo que se tiene o se es en común resulta de la alteridad en cuanto impropiedad compartida. Para decirlo en sus palabras: "no es lo propio, sino lo impropio -o, más drásticamente, lo otro- lo que caracteriza a lo común” (ESPOSITO, 2003, p. 31). Esta idea volvemos a encontrarla de forma casi idéntica en textos posteriores de Esposito. Por ejemplo, cuando escribe: “'común’ es el contrario exacto de 'propio': común es aquello que no es propio, ni apropiable por parte de nadie, que es de todos y/o, por lo menos, de muchos -y que, por lo tanto, no se refiere a sí mismo, sino a lo otro" (ESPOSITO, 2009, p. 97).

Si bien la lectura espositeana pone el énfasis en el munus, noción ambivalente que es tanto la raíz de la communitas como de la immunitas -vale decir, de lo que une a partir de una deuda recíproca y de lo que dispensa de todo deber hacia el otro-, no hay que perder de vista su interpretación del cum, del "con" inscripto en la comunidad y lo común. Situado en la perspectiva 
de Heidegger, la misma que fuera adoptada y adaptada por Nancy, Esposito define el cum en términos ontológicos. El "con" es la relación constitutiva de todo lo que existe. O bien, según otra formulación posible, es el sentido de la existencia en cuanto co-existencia. El "con" designa el origen sin fondo ni fundamento último donde no hay lo Uno, ni siquiera lo uno y lo otro, sino desde siempre lo uno con lo otro: origen múltiple donde el "nosotros" -o el "nos-otros", como prefiere decir Esposito- antecede al "yo", al ego o al ipse.

Mediante este examen del cum y del munus se pone en marcha un poderoso dispositivo hermenéutico que intenta poner en evidencia la contradicción inherente a las filosofías de la comunidad arraigadas en la subjetividad o la intersubjetividad. Pues si lo que caracteriza a lo común es lo impropio, entonces es la exposición a lo otro de sí, y no el sujeto individual o colectivo, lo que hace y define a la comunidad. En todo caso, es importante retener que el "con", pero también el "en" y el "entre", al igual que todas las figuras relacionales que tanto Esposito como Nancy utilizan para dar cuenta de lo común, comportan un valor deliberadamente ambiguo. Ser o estar en común es la condición ontológica de la existencia, sin convertirse por ello en garantía de la vida, y menos aún de la vida buena. En la convivencia emergen como sucesos igualmente posibles la unión y la división, la concordia y la discordia, el intercambio pacífico y el intercambio violento o incluso mortal. Precisamente porque relacionarse es exponerse, la amenaza nunca deja de estar latente entre "nos-otros". Esposito ha dedicado buena parte de su carrera académica a dilucidar el sentido de la relación entre los humanos en su vertiente comunitaria, inmunitaria y biopolítica. Y lo ha hecho, por lo demás, en contrapunto a las grandes interpretaciones de la filosofía política y absteniéndose de formular un programa o proyecto político, con plena conciencia de que su trabajo está encaminado a crear nuevos conceptos antes que a proponer pautas de acción determinadas. No es de extrañar, entonces, que lo común se presente aquí menos como un término político que como un término ontológico desde el cual se intenta repensar la política en clave deconstructiva y más concretamente impolítica ${ }^{6}$.

\section{Consideraciones finales: Políticas y ONTOlogías de Lo COMÚN}

A esta altura es notorio que el principal motivo de los diferendos entre la posición de Laval y Dardot, por una parte, y la de sus colegas, por otra,

${ }^{6}$ Sobre lo impolítico como clave de lectura deconstructiva del léxico político occidental, véase Esposito (2006b). 
radica en el punto de partida para pensar lo común. Aquellos sostienen una posición constructivista donde lo común, lejos de ser la realidad constitutiva de los seres humanos, es el resultado de la praxis política. Hemos sugerido que este argumento se mantiene casi hasta el final de su libro. Sin embargo, en el "Post-scriptum..." de Común el argumento se tuerce hasta el punto de desvirtuarse. Al redefinir el principio de lo común de forma arcaica, como aquello que "aparece primero y funda todo el resto", el constructivismo teórico se vuelve un naturalismo originarista, típicamente metafísico. Ahora bien, si se pone entre paréntesis este vuelco sorpresivo en la argumentación, sería justo decir que la orientación teórico-práctica que predomina a lo largo de Común es una muy diferente. Quizás esta pueda resumirse -al menos en el aspecto que ahora nos interesa destacar- a partir de la siguiente afirmación: “[...] en la medida en que lo común depende exclusivamente de las prácticas del uso colectivo, por fuerza debe excluir categóricamente toda ontología de lo común" (LAVAL Y DARDOT, 2015, p. 312). Para Laval y Dardot, los discursos ontológicos actuales comparten la suposición de que lo común y el ser, lo común y lo real, son nombres diferentes para decir lo mismo. Según ellos, esta suposición forma parte de un pensamiento transhistórico y transmundano que hay que evitar si lo que se pretende es afirmar la primacía de la política sobre la ontología.

Analizaremos a continuación los cuestionamientos específicos que, desde esta visión particular, apuntan a las teorías de Hardt y Negri, Nancy y Esposito. Estas reciben un tratamiento diferenciado conforme a sus rasgos distintivos y, muy especialmente, conforme a la relación que cada una de ellas guarda con la acción política. Dicho esto, no debería sorprender la centralidad que tiene la obra de Hardt y Negri en Común. Por afinidad política y hasta cierto punto también intelectual, Laval y Dardot le consagran mayor atención que a las obras de los otros dos autores, sin que ello redunde en ningún tipo de concesión interpretativa. Le reconocen, sí, "el mérito histórico de hacer pasar la reflexión del plano de las experiencias concretas de los commons (en plural) a una concepción más abstracta y políticamente más ambiciosa de lo común (en singular)" (LAVAL Y DARDOT, 2015, p. 22). Para Laval y Dardot, la "teoría de lo común" de Hardt y Negri "constituye un hito en la historia de los pensamientos críticos" aunque "por desgracia está hipotecada por presupuestos que [...] no se sostienen” (LAVAL Y DARDOT, 2015, p. 67). Básicamente, aquéllos les reprochan a éstos tres errores insostenibles: repetir sin siquiera saberlo la doctrina de Proudhon, quien concibe lo común como una fuerza colectiva espontánea y la explotación como un robo; atribuir al 
trabajo inmaterial una autonomía excesiva respecto al proceso de valorización del capital en su forma actual; y caer presos de un optimismo ingenuo al entrever en el desarrollo de la producción biopolítica una anticipación del comunismo por venir. Estos aparentes errores, lógicamente encadenados entre sí, compartirían un mismo origen. En principio, el problema de la teoría de Hardt y Negri se debe a que estos tienen una idea ilusoria acerca de la "génesis de lo común" (LAVAL; DARDOT, 2015, p. 256). Dicho sin rodeos, la objeción principal recae sobre el hecho de que lo común no es solamente algo producido por la actividad conjunta de los miembros de la sociedad, sino también la condición previa de la producción misma. Es la dimensión ontológica del concepto de lo común la que provoca la crítica más áspera de esta teoría, a la cual se trata en numerosas ocasiones de "espontaneísta", y, como consecuencia de ello, de ser proclive a "cierto quietismo" en términos políticos (LAVAL Y DARDOT, 2015, p. 222).

Los cuestionamientos de Laval y Dardot a Nancy y Esposito son ciertamente de otro orden. Aunque la objeción fundamental contra las tesis de ambos autores sea en el fondo la misma que la que le hacen a Hardt y Negri: poner lo común en el centro de sus respectivas ontologías. Como hemos visto, tanto los legados filosóficos que inspiran a unos y otros como las relaciones de cada una de estas concepciones con la política resultan divergentes. De ahí el trato diferenciado que reciben en la interpretación de Laval y Dardot. Para estos últimos, la primacía ontológica que tanto Nancy como Esposito conceden a lo común en sus elaboraciones filosóficas sería la razón por la cual resulta imposible deducir de ellas una política. El caso de Nancy es sin duda el más problemático desde este punto de vista, ya que su intento por separar la política del ser en común tendría como efecto ni más ni menos que "desanimar toda política de lo común" (LAVAL; DARDOT, 2015, p. 312). El caso de Esposito evidencia un defecto similar, aunque acaso más atenuado. La observación que se le hace a su propuesta no tiene tanto que ver con el uso que hace Esposito de la categoría de lo impolítico, como cabría esperar, sino más bien con el hecho de que sus proposiciones afirmativas sobre la política serían contradictorias con la negatividad radical que se encuentra en la base de su planteo sobre lo común y la comunidad (LAVAL Y DARDOT, 2015, p. 317). En la misma línea, se cuestiona a ambos filósofos por la radicalización que llevan a cabo del "ser-con" heideggeriano y que, según esta lectura, conduce a una hipóstasis del cum cuyo resultado es la desvinculación de lo común respecto del mundo y por consiguiente de la política. 
Hacia el final del breve apartado donde se encuentran estas críticas, leemos: "Todas estas iniciativas tropiezan, de hecho, en una misma dificultad de principio: una vez afirmada la prioridad de la ontología, el paso a la política sólo puede consistir en un salto, simplemente porque la apuesta de deducir una política de la ontología es imposible de cumplir" (LAVAL; DARDOT, 2015, p. 317). A primera vista, las iniciativas a las que se hace mención parecen ser exclusivamente las de Nancy y Esposito. Sin embargo, una nota a pie de página ańadida al pasaje que acabamos de citar reenvía a un libro de Dardot, Laval y El Mouhoub Mouhoud consagrado a revisar críticamente la obra de Hardt y Negri (DARDOT et al., 2007). Allí encontramos un fragmento del mismo pasaje, pero esta vez en referencia directa a la iniciativa de los autores de Imperio: "la apuesta de deducir una politica de la ontología es imposible de cumplir" (DARDOT et al., 2007, p. 253, el énfasis es de Dardot, Laval y Mouhoud). Al menos en este aspecto decisivo, las distintas iniciativas interrogadas quedan igualadas por la imposibilidad común de cumplir sus apuestas.

Si subrayamos una y otra vez, como venimos haciendo, la disputa interpretativa en torno a la preeminencia, ya de la política, ya de la ontología, para definir lo común, es porque creemos que ella representa el espacio por antonomasia donde se cruzan los significados diversos y para el caso opuestos que hacen de lo común un concepto equívoco. Desde luego, no es el único. La equivocidad en cuestión afecta muchas otras dimensiones de esta categoría tanto en la utilización que se hace de ella por parte de discursos a todas luces diferentes como en el uso que se le da al interior de los mismos discursos. En todo caso, la distinción entre un punto de partida político y otro ontológico permite delinear los contornos de los principales posicionamientos que hoy asumen las teorías sobre lo que es común. Por si hace falta aclararlo, no pensamos aquí en un delineamiento que fijaría límites infranqueables. La idea de un hiato semejante no se corresponde con el estado real de las discusiones sobre el tema. Por una parte, observamos que los teóricos que afirman una ontología, cualquiera sea esta, no sostienen en ningún momento, ni de manera explícita ni implícita, una exclusión de la política. Esto es evidente en los trabajos de Hardt y Negri donde la instancia ontológica y la política aparecen mutuamente vinculadas, y menos evidente, aunque por cierto demostrable, en aquellos otros de Nancy y Esposito donde la articulación de estas instancias supone la subordinación de la segunda a la primera. Por otra parte, vemos que la empresa de Laval y Dardot, para quienes la política es el suelo y el horizonte históricos de todo cuanto es común en el mundo humano, no clausura del todo la posibilidad 
de una ontología. En un breve pero significativo pasaje de Común, después de recordar la conocida frase de Gilles Deleuze y Félix Guattari, "antes del ser, hay la política", afirman que "la única ontología todavía posible es la que Foucault llamaba 'ontología de la actualidad'” (LAVAL Y DARDOT, 2015 , p. 317). Afirmación que hay que leer, creemos, menos como un gesto concesivo a las iniciativas cuestionadas en su libro que como un signo de apertura hacia una consideración histórico-práctica del ser, directamente relacionada con las problemáticas de la verdad, el poder y la moral.

A modo de conclusión, postulamos que la equivocidad o la ambigüedad que atraviesa las teorías y los debates sobre lo común constituye un problema irreductible. Con esto queremos decir que no se trata de un problema susceptible de solución, como si de hecho fuera posible optar excluyentemente entre una significación política y otra ontológica. Ambas significaciones cohabitan en una tensión permanente, de manera más o menos pacífica o violenta según los casos. Si se adopta una visión retrospectiva del recorrido efectuado hasta aquí, se puede deducir que el surgimiento y las derivas polémicas de la cuestión de lo común son inseparables de la relación siempre tensa entre ontología y política. Esta relación asume por lo general una gran variedad de formas no necesariamente compatibles. Lo que a nuestro parecer habría que evitar es intentar suprimirla, ya sea mediante una identificación que borraría los aportes que cada uno de estos sentidos representa, ya sea por medio de una diferenciación absoluta que daría lugar a posiciones extremas e igualmente dogmáticas. El politicismo y el filosofismo son posiciones unívocas y por eso mismo inadecuadas para pensar una cuestión que por su irreductible problematicidad exige aproximaciones plurívocas y a la vez complementarias. En sentido ontológico, común es el modo en que los individuos somos o estamos $y$, por tanto, actuamos en el mundo, desde el momento en que se reconoce la singularidad o la unicidad, la multiplicidad y el relacionamiento como condiciones compartidas por todos. En sentido político, común es el nombre de una lógica de organización social, económica y jurídica que, sobre la base de nuevas instituciones democráticas, busca garantizar para cada individuo el acceso igualitario al mundo material e inmaterial que compartimos por el hecho de existir juntos y no de otra manera. Un sentido no va sin el otro, no se entiende ni se explica enteramente sin el otro. La simple prescindencia de alguna de estas aproximaciones equivaldría a negar no solo uno de los vectores significantes privilegiados en los pensamientos y las experiencias de lo común, sino también aquello que hace de este concepto uno de los problemas más convocantes de nuestro tiempo. 
ALVARO, D. The common: reflections on an equivocal concept. Trans/form/ação, Marília, v. 43, n. 4, p. 89-110 Out./Dez., 2020.

\begin{abstract}
This article aims to reflect on the definitions and theories of the "common" that nourish the contemporary debates around that concept. With that goal, we will interrogate the works of Christian Laval and Pierre Dardot, Michael Hardt, Antonio Negri, Jean-Luc Nancy and Roberto Esposito. The analysis of these discourses will make evident that what nowadays is understood by common, both from a philosophical and from a practical-political viewpoint, assumes different and usually confronted meanings. The article looks into the diverse meanings and uses of the concept in order to demonstrate that this semantic ambivalence is a decisive factor to understand the scope and limitations of the problem of the common in today's world.
\end{abstract}

Keywords: Common. Commons. Equivocity. Politics. Ontology.

\title{
Bibliografía
}

AGAMBEN, G. La comunidad que viene. Valencia: Pre-Textos, 2006 [1990].

BADIOU, A.; ŽIŽEK, S. (Eds.). L'idée du communisme, 2. Paris: Lignes, 2010.

BLANCHOT, M. La comunidad inconfesable. Madrid: Arena, 2002 [1983].

DARDOT, P. et al. Sauver Marx? Empire, multitude, travail immatériel. Paris: La Découverte, 2007.

ESPOSITO, R. Communitas. Origen y destino de la comunidad. Buenos Aires: Amorrortu, 2003 [1998].

ESPOSITO, R. Immunitas. Protección y negación de la vida. Buenos Aires: Amorrortu, 2005.

ESPOSITO, R. Bíos. Biopolítica y filosofía. Buenos Aires: Amorrortu, 2006a.

ESPOSITO, R. Categorías de lo impolítico. Buenos Aires: Katz, 2006b [1988, 1999].

ESPOSITO, R. Comunidad, inmunidad y biopolítica. Madrid: Herder. 2009.

HARDT, M.; NEGRI, A. Imperio. Buenos Aires: Paidós, 2002.

ESPOSITO, R. Multitud: guerra y democracia en la era del imperio. Buenos Aires: Debate, 2004.

ESPOSITO, R. Commonwealth. El proyecto de una revolución del común. Madrid: Akal, 2011. 
ESPOSITO, R. Declaración. Madrid: Akal, 2012.

ESPOSITO, R. Asamblea. Madrid: Akal, 2019.

HOUNIE, A. (Comp.). Sobre la idea del comunismo. Buenos Aires: Paidós, 2010.

LAVAL, C; DARDOT, P. Común. Ensayo sobre la revolución en el siglo XXI. Barcelona: Gedisa, 2015.

LAVAL, C; DARDOT, P. La nueva razón del mundo. Ensayo sobre la sociedad neoliberal. Barcelona: Gedisa, 2013.

LAVAL, C; DARDOT, P. La pesadilla que no acaba nunca. El neoliberalismo contra la democracia, Barcelona: Gedisa, 2017.

NANCY, J.-L. La comunidad inoperante, Santiago de Chile: LOM/ARCIS, 2000 [1986, 1990].

NANCY, J.-L. ¿Todo es político? (simple nota). In: BALIBAR, É. et al. ¿Pensamiento único en filosofía política? Buenos Aires: Kohen \& Asociados Internacional, 2001. p. 59-63.

NANCY, J.-L. “Con” Jean-Luc Nancy. Entrevista con Stéphane Gatti y Michael

Séonnet. In: NANCY, J.-L. La verdad de la democracia. Buenos Aires: Amorrortu, 2009.

NANCY, J.-L. La comunidad revocada. Buenos Aires: Mardulce, 2016.

SAIDEL, M. Reinvenciones de lo común: hacia una revisión de algunos debates recientes. Revista de Estudios Sociales, n. 70, octubre-diciembre, p. 10-24, 2019.

TAEK-GWANG LEE, A.; ŽIŽEK, S. (Eds.). La idea de comunismo. The Seoul Conference (2013). Madrid: Akal, 2018.

ŽIŽEK, S. (Ed.). La idea de comunismo. The New York Conference (2011). Madrid: Akal, 2014.

Recebido: 21/1/2020

Aceito: 22/02/2020 